\title{
Analisis Senyawa Alkaloid dan Uji Daya Hambat Ekstrak Buah Sirih (Piper betle L)
} terhadap Bakteri Staphylococcus epidermidis

\section{Regina F. Tjandra, ${ }^{1}$ Fatimawali, ${ }^{1}$ Olvie S. Datu ${ }^{1}$}

\author{
${ }^{1}$ Program Studi Farmasi Fakultas Matematika Ilmu Pengetahuan Alam Universitas Sam \\ Ratulangi Manado \\ Email: reginaftjandra@gmail.com
}

\begin{abstract}
Betel fruit contains saponins, tannins, alkaloids, flavonoids, and steroids which are antibacterial compounds. Alkaloids are one of the secondary metabolites that are found in nature and have physiological activity. This study aims to determine the presence of alkaloid content in betel fruit and to determine the inhibitory activity of betel fruit extract against Staphylococcus epidermidis bacteria. This study is using the disc method in the antibacterial test, TLC method, color reaction and UV-Vis spectrophotometry to determine the presence of alkaloids in betel fruit. The results showed that betel extract contained alkaloids, as evidenced by the presence of orange stains on TLC with chloroform: methanol (1:4) eluent sprayed with Dragendrof reagents. UV-Vis spectrophotometer analysis results, the alkaloids are at a maximum wavelength of $282 \mathrm{~nm}$. The results of the antibacterial activity test of betel extract against Staphylococcus epidermidis shows that the concentration of $10 \%$ and $20 \%$ had a strong antibacterial activity with an average inhibition zone of $12.8 \pm 1.40 \mathrm{~mm}$ and $15.03 \pm$ $0.723 \mathrm{~mm}$ and a concentration of $40 \%$ had Antibacterial activity is very strong with an average inhibition zone of $21.53 \pm 1.530 \mathrm{~mm}$. In conclusion, betel fruit extract contains alkaloid compounds and has antibacterial activity with strong to very strong categories.
\end{abstract}

Keywords: Betel Fruit (Piper betle L), Alkaloids, Antibacterial, Staphylococcus epidermidis.

\begin{abstract}
Abstrak: Buah sirih memiliki kandungan saponin, tanin, alkaloid, flavonoid, dan steroid yang merupakan senyawa antibakteri. Alkaloid merupakan salah satu metabolit sekunder yang banyak ditemukan di alam dan mempunyai aktivitas fisiologis. Penelitian ini bertujuan untuk mengetahui adanya kandungan alkaloid pada buah sirih dan untuk mengetahui adanya aktivitas daya hambat dari ekstrak buah sirih terhadap bakteri Staphylococcus epidermidis. Penelitian ini menggunakan metode cakram pada uji antibakteri, metode KLT, reaksi warna dan Spektrofotometri UV-Vis untuk mengetahui adanya alkaloid pada buah sirih. Hasil penelitian menunjukkan bahwa ekstrak buah sirih memiliki kandungan alkaloid, terbukti dengan adanya noda berwarna jingga pada KLT dengan eluen kloroform:methanol (1:4) yang disemprotkan pereaksi Dragendrof. Hasil analisis Spektrofotometer UV-Vis, alkaloid tersebut berada pada panjang gelombang maksimum $282 \mathrm{~nm}$. Hasil uji aktivitas antibakteri ekstrak buah sirih terhadap bakteri Staphylococcus epidermidis diperoleh bahwa konsentrasi $10 \%$ dan $20 \%$ memiliki aktivitas antibakteri kuat dengan zona hambat rata-rata sebesar 12,8 $\pm 1,40 \mathrm{~mm}$ dan $15,03 \pm 0,723 \mathrm{~mm}$ serta konsentrasi $40 \%$ memiliki aktivitas antibakteri sangat kuat dengan zona hambat rata-rata sebesar $21,53 \pm 1,530 \mathrm{~mm}$. Sebagai kesimpulan ekstrak buah sirih mengandung senyawa alkaloid dan memiliki aktifitas antibakteri dengan kategori kuat sampai sangat kuat.
\end{abstract}

Kata kunci : Buah Sirih (Piper betle L), Alkaloid, Antibakteri, Staphylococcus epidermidis

\section{PENDAHULUAN}

Di Indonesia, dikenal lebih dari 20.000 jenis tumbuhan obat, namun \pm 1.000 jenis tumbuhan yang baru terdata dan yang dimanfaatkan hanya \pm 300 sebagai obat tradisional. $^{1}$ Bahan obat tradisional baik 
yang berasal dari hewan maupun dari tumbuhan banyak digunakan untuk mengatasi berbagai masalah kesehatan sejak zaman dahulu. Pengobatan dengan obat tradisional merupakan salah satu alternatif untuk memenuhi kebutuhan dasar masyarakat dibidang kesehatan. ${ }^{2}$

Penggunaan ekstrak tumbuhan yang memiliki aktivitas antimikroba sangat membantu dalam penyembuhan. Salah satu tanaman yang memiliki kemampuan sebagai antibakteri adalah Sirih hijau (Piper betle L.). ${ }^{3}$ Daun sirih hijau digunakan sebagai obat batuk, obat cacing, dan antiseptik luka. Daun sirih hijau mengandung berbagai macam kandungan kimia, antara lain minyak atsiri, terpinen, seskuiterpen, fenilpropan, dan terpen. Terdapat pula katekin dan tannin yang termasuk senyawa polifenol. Selain itu terkandung juga alkaloid, flavonoid, fenol dan steroid. ${ }^{4}$

Penelitian yang dilakukan oleh Darmawati mengenai isolasi dan karakterisasi alkaloid dari daun sirih merah menunjukan bahwa daun sirih merah miliki kandungan senyawa alkaloid dengan jenis amina primer alifatik. ${ }^{5}$ Berdasarkan penelitian itu, peneliti tertarik melakukan penelitian isolasi dan identifikasi senyawa alkaloid dari ekstrak daun sirih hijau untuk mengetahui jenis alkaloid yang terdapat dalam daun sirih hijau.

Alkaloid merupakan salah satu metabolit sekunder yang banyak ditemukan di alam dan mempunyai aktivitas fisiologis. Alkaloid memiliki kemampuan sebagai antibakteri dengan mekanisme mengganggu komponen penyusun peptidoglikan pada sel bakteri, sehingga lapisan dinding sel tidak terbentuk secara utuh dan menyebabkan kematian sel tersebut. ${ }^{6}$

Bakteri Propionibacterium acnes dan bakteri Staphylococcus epidermidis merupakan penyebab dari penyakit jerawat yang banyak di derita masyarakat terutama remaja. Bakteri ini merupakan flora normal di kulit, namun dapat bersifat invasif. Penyebab lain adanya zat nutrisi bagi bakteri yang diproduksi dari sekresi kelenjar sebasea yakni air, asam amino, urea, garam dan asam lemak. Bakteri ini berperan pada proses kemotaktik inflamasi serta pembentukan enzim lipolitik pengubah fraksi sebum menjadi massa padat, yang menyebabkan terjadinya penyumbatan pada saluran kelenjar sebasea.

\section{METODE PENELITIAN}

Penelitian ini dilakukan pada bulan Oktober 2019 - Februari 2020 di laboratorium Farmasi Lanjutan Program Studi Farmasi Fakultas Matematika dan Ilmu Pengetahuan Alam Universitas Sam Ratulangi Manado. Adapun jenis penelitian ini adalah penelitian eksperimental laboratorium.

Sampel diambil dari desa Komba, Kecamatan Sentani, Kabupaten Jayapura, Papua, dengan ketinggian tempat 500 meter diatas permukaan laut dengan lintang utara $2^{\circ} 333^{\prime} 52.7^{\prime \prime}$ dan lintang selatan $140^{\circ} 30^{\prime}$ 39.0".

Identifikasi tanaman dilakukan di Laboratorium Taksonomi Tumbuhan, Jurusan Biologi, Fakultas Matematika dan Ilmu Pengetahuan Alam, Universitas Sam Ratulangi Manado.

Ekstraksi. Sebanyak 582 g serbuk kering buah sirih yang sudah diayak diekstraksi dengan cara maserasi. Proses maserasi dilakukan dengan merendam sampel dengan etanol $96 \%$ sebanyak 3 Liter selama $5 \times 24$ jam pada suhu ruang. Filtrat yang diperoleh disaring kemudian dievaporasi hingga di dapat ekstrak kental.

Isolasi alkaloid. Ekstrak dipartisi menggunakan campuran kloroform-air (1:1) dengan melarutkan ekstrak terlebih dahulu dalam kloroform. Lapisan kloroform (bagian bawah) dipisahkan dan diekstraksi dengan asam asetat 5\% hingga terbentuk 2 lapisan. Lapisan asam (bagian atas) dipisahkan dan dibasakan dengan $\mathrm{NH}_{4} \mathrm{OH}$ pekat hingga $\mathrm{pH}$ 9-10, lalu diekstraksi kembali dengan kloroform. Lapisan kloroform dipisahkan dan dipekatkan dengan penguap putar hingga diperoleh ekstrak alkaloid total.

Uji kromatografi lapis tipis. Uji pendahuluan di awali dengan diawasi plat KLT pada oven dengan suhu $105^{\circ} \mathrm{C}$ selama 10 menit. Fase diam yang digunakan adalah 
silika gel F254 dan fase gerak yang digunakan untuk mengelusi yaitu, kloroform: metanol (1:4). Bercak yang terbentuk diamati dengan sinar tampak, lampu UV 254 dan $366 \mathrm{~nm}$, kemudian disemprotkan pereaksi Dragendorf. Hasil positif akan ditunjukkan oleh noda jingga.

Spektrofotometri ultraviolet (UVVis). Spektrum UV-Vis diukur menggunakan pelarut metanol p.a dengan nilai cutoff $205 \mathrm{~nm}$. Pengukuran diawali dengan perlakuan baseline (nilai serapan pelarut dibuat 0), sehingga hasil yang terukur merupakan serapan dari sampel. Spektrum UV-Vis menampilkan hubungan panjang gelombang dan nilai serapan (absorbans). Ciri khas senyawa alkaloid ialah adanya atom nitrogen yang memiliki pasangan elektron bebas. Atom nitrogen ini menyerap sinar UV pada panjang gelombang $>270 \mathrm{~nm}$ (Nururrahmah, 2013).

Peremajaan kultur murni bakteri. Satu koloni biakan murni bakteri Staphylococcus epidermidis diambil dengan menggunakan ose steril dari kultur murninya, dipakai untuk peremajaan bakteri 4 tabung reaksi setiap tabung diisi $7 \mathrm{~mL}$ larutan nutrien agar dan selanjutnya diinokulasikan dalam medium nutrien agar (NA) miring, kemudian diinkubasikan dalam inkubator pada suhu $37^{\circ} \mathrm{C}$ selama 1x24 jam.

Pembuatan larutan McFarland 0,5. Larutan $\mathrm{H}_{2} \mathrm{SO}_{4} \quad 1 \%$ sebanyak $9,95 \mathrm{~mL}$ dicampurkan dengan larutan $\mathrm{BaCl}_{2} \cdot 2 \mathrm{H}_{2} \mathrm{O}$ $1,175 \%$ sebanyak $0,05 \mathrm{~mL}$ dalam erlenmeyer. Kemudian dikocok sampai terbentuk larutan yang keruh. Kekeruhan ini dipakai sebagai standar kekeruhan suspensi bakteri uji.

Pembuatan suspensi uji bakteri. Bakteri uji pada media agar miring diambil dengan menggunakan kawat ose steril lalu disuspensikan ke dalam tabung yang berisi $15 \mathrm{~mL}$ larutan $\mathrm{NaCl} 0,9 \%$ dalam tabung reaksi kemudian dikocok hingga diperoleh larutan yang keruh. Kekeruhan ini dipakai sebagai standar kekeruhan suspensi bakteri uji.

Penyiapan larutan uji dan larutan kontrol. Ditimbang ekstrak kental buah sirih sebanyak 0,5 g untuk konsentrasi $10 \%, 1 \mathrm{~g}$ untuk konsentrasi $20 \%$ dan $2 \mathrm{~g}$ untuk konsentrasi $40 \%$ dan dilarutkan dalam larutan DMSO 10\% sampai $5 \mathrm{~mL}$. Kontrol negatif adalah larutan DMSO $10 \%$. Dan kontrol positif kertas cakram tetrasiklin konsentrasi $30 \mu \mathrm{g}$.

Pengujian daya hambat sampel terhadap bakteri uji. Medium NA sebanyak $100 \mathrm{~mL}$ dicampur suspensi bakteri sebanyak $3 \mathrm{~mL}$ lalu dimasukkan ke dalam cawan petri masing-masing sebanyak $30 \mathrm{~mL}$ lalu dibiarkan memadat, kemudian dimasukkan masing-masing kertas cakram yang telah diteteskan ekstrak etanol secara aseptis menggunakan pinset steril dan sebagai kontrol positif (+) digunakan kertas cakram tetrasiklin serta sebagai kontrol negatif (-) digunakan larutan DMSO 10\%. Kertas cakram yang telah mengandung ekstrak dimasukkan ke dalam permukaan medium dengan jarak kertas cakram satu dengan yang lainnya $2-3 \mathrm{~cm}$ dipinggir cawan petri. Kemudian diinkubasi pada suhu $37^{\circ} \mathrm{C}$ selama $1 \times 24$ jam. Diamati zona bening yang terbentuk dan diukur diameter daerah hambatnya dengan jangka sorong.

Pengolahan data. Data-data diameter hambat dan variasi kosentrasi hasil pengujian aktivitas antibakteri dilakukan analisa data dengan One-Way ANOVA.

\section{HASIL PENELITIAN}

Hasil yang didapat dalam ektrasi tanaman buah sirih dari bobot kering $582 \mathrm{~g}$ menjadi ektrak kental yaitu 72,39 g dengan pelarut etanol 96\%. Gambar 1 menunjukkan hasil isolasi alkaloid dengan KLT yang ditandai dengan warna jingga dan gambar 2 menunjukkan hasil isolasi alkaloid dengan spektrofotometer UV-Vis pada panjang gelombang $282 \mathrm{~nm}$.

Tabel 2 merupakan hasil uji normalitas shapiro-wilk yang menunjukkan bahwa data memiliki nilai $\mathrm{p}>0,05$ berarti data tersebut terdistribusi normal. Data yang terdistribusi normal merupakan syarat dari data parametric sehingga dapat dilakukan pengujian dengan menggunakan One Way Anova. 


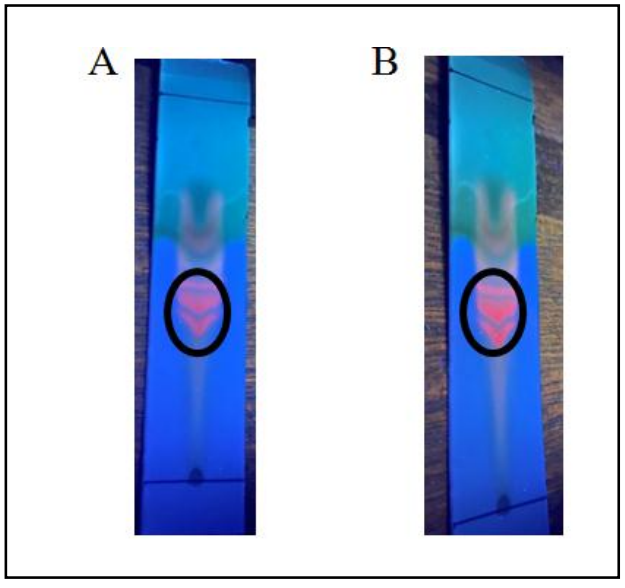

Gambar 1. Hasil KLT dan KLT Preparatif ekstrak alkaloid dengan eluen kloroform: metanol $(0,5 \mathrm{ml}: 2 \mathrm{ml})$. panjang gelombang $\mathrm{UV} \lambda_{366}$

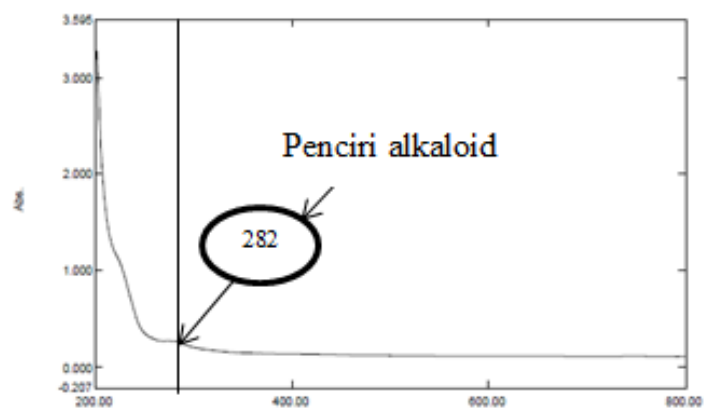

Gambar 2. Spektrum UV - Vis.

Tabel 1. Hasil pengukuran diameter zona hambat

\begin{tabular}{llllll}
\hline $\begin{array}{l}\text { Pengulangan } \\
\text { yang } \\
\text { dilakukan }\end{array}$ & $\begin{array}{l}\text { Kontrol } \\
\text { negatif } \\
(\mathrm{mm})\end{array}$ & $\begin{array}{l}\text { Kontrol } \\
\text { positif(mm) }\end{array}$ & \multicolumn{3}{l}{ Tiap konsentrasi Ekstrak (mm) } \\
\hline I & 0 & 0 & $10 \%$ & $20 \%$ & $40 \%$ \\
II & 0 & 6,5 & 12,8 & 11,7 & 14,7 \\
III & 0 & 9,5 & 14,2 & 15,5 & 22,1 \\
Rata-rata & $0 \pm 0,00$ & $7,1 \pm 2,163$ & $12,8 \pm 1,40$ & $15,03 \pm 0,723$ & $21,53 \pm 1,530$ \\
\hline
\end{tabular}

Tabel 2. Uji normalitas Shapiro-Wilk

\begin{tabular}{lll}
\hline Normalitas Shapiro-Wilk & Sig \\
\hline Zona Hambat & Kontrol positif & 0.537 \\
& Konsentrasi $10 \%$ & 1.000 \\
& Konsentrasi $20 \%$ & 0.132 \\
& Konsentrasi $40 \%$ & 0.377 \\
\hline
\end{tabular}

Tabel 3. Uji varians data

\begin{tabular}{lll}
\hline Uji Varians & & Sig \\
\hline Zona Hambat & Based on mean & 0.077 \\
& Based on median & 0.494 \\
& Based on median and with adjusted df & 0.515 \\
& Based on trimmed means & 0.090 \\
\hline
\end{tabular}

Tabel 3 menunjukkan bahwa nilai $\mathrm{p}>$ 0,05 , yang berarti data yang ada di dalam penelitian ini memiliki varian yang sama sehingga dapat dilakukan pengujian dengan menggunakan One Way Anova.

Tabel 4. Uji One Way Anova

\begin{tabular}{lll}
\hline ANOVA & Sig \\
\hline Zona Hambat & Kelompok perlakuan ekstrak buah sirih & 0.000
\end{tabular}

Tabel 4 menunjukkan bahwa hasil uji One Way Anova terhadap kelompok perlakuan ekstrak etanol buah sirih memiliki nilai $p=0,000$. Karena nilai $p<0,05$ maka nilai rata-rata antar kelompok perlakuan ekstrak etanol buah sirih adalah berbeda bermakna. Untuk mengetahui kelompok perlakuan yang memiliki perbedaan bermakna tersebut, maka selanjutnya dilakukan analisis post-hoc.

Tabel 5. Uji Analisis Post-Hoc (LSD)

\begin{tabular}{|c|c|c|c|c|c|}
\hline & $10 \%$ & $20 \%$ & $40 \%$ & $\begin{array}{l}\text { Kontrol } \\
\text { Positif }\end{array}$ & $\begin{array}{l}\text { Kontrol } \\
\text { Negatif }\end{array}$ \\
\hline $10 \%$ & - & 0,075 & $0,000^{*}$ & $0,000 *$ & $0,000^{*}$ \\
\hline $20 \%$ & 0,075 & - & $0,000 *$ & $0,000 *$ & $0,000^{*}$ \\
\hline $40 \%$ & $0,000 *$ & $0,000^{*}$ & - & $0,000^{*}$ & $0,000^{*}$ \\
\hline Kontrol Positif & $0,000^{*}$ & $0,000 *$ & $0,000 *$ & - & $0,000^{*}$ \\
\hline Kontrol Negatif & $0,000 *$ & $0,000^{*}$ & $0,000 *$ & $0,000 *$ & - \\
\hline
\end{tabular}

Tabel 5 menunjukkan hasil dari uji antibakteri dari tiga konsentrasi yang membuktikan bahwa tiga konsentrasi memiliki perbedaan bermakna.

\section{BAHASAN}

Proses ekstraksi menggunakan metode ekstraksi cara dingin, yaitu maserasi menggunakan $3000 \mathrm{~mL}$ pelarut etanol 96\%, 
proses maserasi dilakukan selama 5 hari hingga diperoleh ekstrak kental sebanyak 72,39 g. Metode maserasi dipilih karena cara pengerjaan sederhana, peralatan yang mudah di dapat dan tidak memerlukan alat khusus, biaya operasionalnya relatif rendah, tanpa pemanasan. Proses ekstraksi dilakukan dengan menggunakan pelarut Etanol 96\% karena pelarut ini menyari hampir keseluruhan kandungan simplisia baik non polar, semi polar, maupun polar. ${ }^{8}$ Pelarut ini bersifat selektif, tidak beracun dan bersifat universal yang cocok untuk mengekstrak semua golongan senyawa metabolit sekunder. ${ }^{9}$

Alkaloid diisolasi berdasarkan prinsip ekstraksi asam-basa. Alkaloid memiliki sifat basa dari atom nitrogen penyusunnya. Umumnya alkaloid di dalam tumbuhan terikat dengan asam organik membentuk garam. Garam alkaloid ini yang kemudian diekstraksi dengan pelarut organik yang sesuai. Pelarut yang digunakan dalam penelitian ini adalah kloroform. Kloroform dapat melarutkan alkaloid dengan baik dan telah umum digunakan dalam proses isolasi. Kloroform memiliki sifat semipolar sehingga dapat dengan baik melarutkan alkaloid. Namun, tidak hanya senyawa alkaloid yang terekstraksi, tetapi juga senyawa metabolit sekunder lainnya yang memiliki kepolaran berdekatan dengan kloroform. ${ }^{10}$ Hal ini telah dibuktikan oleh Hsieh yang menemukan senyawa diterpenoid, steroid, dan asetogenin juga terlarut dalam kloroform. ${ }^{11}$

Larutan asam organik atau anorganik digunakan untuk memisahkan alkaloid dari senyawa metabolit sekunder lain yang ikut terekstraksi dalam kloroform. Alkaloid akan terlarut dalam larutan asam karena kondisinya dalam bentuk garam. Penambahan $\mathrm{NH}_{4} \mathrm{OH}$ bertujuan melepaskan ikatan alkaloid dengan asamnya sehingga alkaloid kembali berada dalam kondisi bebas. Penambahan $\mathrm{NH}_{4} \mathrm{OH}$ dihentikan pada $\mathrm{pH}$ 9-10. Selanjutnya alkaloid dalam kondisi bebas dapat diekstraksi dengan pelarut kloroform. Untuk menentukan banyaknya senyawa alkaloid yang tereks-traksi, dilakukan uji KLT, lalu keberadaan alkaloid dideteksi secara kualitatif dengan menyemprotkan pereaksi Dragendorf pada kromatogram.

Isolat alkaloid yang didapat selanjutnya dianalisis menggunakan kromatografi lapis tipis untuk mengetahui jumlah komponennya. Isolat alkaloid yang didapat kemudian dilakukan pemisahan dengan menggunakan KLT fase gerak eluen kloroform : metanol (1:4). Hasil KLT menggunakan plat silika gel $\mathrm{GF}_{254}$ dan fasa gerak yang digunakan adalah campuran pelarut kloroform : metanol (1:4).

Pada hasil KLT menunjukkan noda yang terlihat jelas berwarna jingga dibawah sinar UV 366 yang berarti menunjukkan adanya alkaloid (Gambar 1). Hal ini sebanding dengan penelitian yang dilakukan sebelumnya yang menggunakan isolasi dari daun bidara arab hasil KLT yang didapat pada sinar UV 366 yaitu noda yang berwarna jingga. Dengan nilai Rf yang didapat yaitu 0,275. Berdasarkan Harbone nilai Rf alkaloid yang paling umum yaitu 0,07 0,62 makanya buah sirih dinyatakan mengandung senyawa alkaloid. ${ }^{12}$

Metode ini digunakan untuk mengidentifikasi senyawa alkaloid yang diperoleh dari pemisahan senyawa dengan KLT. Pengaturan panjang gelombang pada rentang 200-800 nm. Spektrum UV-Vis diukur menggunakan pelarut metanol p.a dengan nilai cutoff $205 \mathrm{~nm}$. Pengukuran diawali dengan perlakuan baseline (nilai serapan pelarut dibuat 0), sehingga hasil yang terukur merupakan serapan dari sampel.

Spektrum UV-Vis (Gambar 2) menampilkan hubungan panjang gelombang dan nilai serapan (absorbans). Nilai serapan diperoleh pada panjang gelombang $282 \mathrm{~nm}$. Ciri khas senyawa alkaloid ialah adanya atom nitrogen yang memiliki pasangan elektron bebas. Atom nitrogen ini menyerap sinar UV pada panjang gelombang $>270 \mathrm{~nm}^{13}$

Dibandingkan dengan penelitian Mella dalam pelarut metanol dan sampel yang digunakan ekstrak daun sirsak hutan terdapat kemiripan adanya alkaloid pada panjang gelombang serapan diperoleh pada panjang gelombang 210, 282, dan 359 
nm. ${ }^{14}$ Dan dibandingkan dengan data UV senyawa O-metilarmepavina Bhaumik dalam pelarut metanol, terdapat kemiripan panjang gelombang antara hasil pengukuran $(282 \mathrm{~nm})$ dan data pembanding (280 $\mathrm{nm}){ }^{15}$

Perbedaan hasil yang didapat pada panjang gelombang ini mungkin disebabkan oleh perbedaan kondisi atau posisi atom nitrogen dalam strukturnya. Dan sampel yang digunakan memang berbeda (Gambar 2).

Metode kertas cakram banyak digunakan untuk menguji daya antibakteri suatu senyawa terhadap bakteri. Pada penelitian ini dapat dilihat bahwa masing-masing konsentrasi dapat membentuk zona hambat pada medium NA yang telah ditumbuhkan bakteri Staphylococcus epidermidis yaitu konsentrasi $10 \%$ dengan rata-rata sebesar $12,8 \pm 1,40 \mathrm{~mm}$ yang berarti memiliki aktivitas antibakteri kuat, $20 \%$ sebesar $15,03 \pm 0,723 \mathrm{~mm}$ yang berarti memiliki aktivitas antibakteri kuat, $40 \%$ sebesar $21,53 \pm 1,530 \mathrm{~mm}$ yang berarti memiliki aktivitas antibakteri sangat kuat, kontrol negative tidak memiliki zona hambat dan kontrol positif memiliki zona hambat rata-

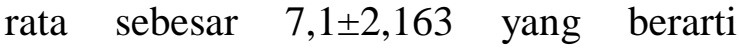
memiliki aktivitas antibakteri sedang (Tabel 2). Data penelitian yang di dapatkan dilakukan uji statistik yaitu uji One Way Anova, sebelum dilakukan uji tersebut harus dilakukan uji normalitas untuk memastikan data berdistribusi normal dan uji varians karena data harus homogen.

Pada penelitian ini berdasarkan hasil uji post-hoc menunjukkan jika data memiliki $\mathrm{p}<0,05$ berarti data tersebut signifikan atau berbeda bermakna dengan konsentrasi lain (Tabel 5). Uji post-hoc menunjukkan diameter zona hambat bakteri Staphylococcus epidermidis untuk konsentrasi $10 \%$ dengan 20\% tidak memiliki perbedaan bermakna, tetapi dengan konsentrasi $40 \%$ dan kontrol negatif serta kontrol positif memiliki perbedaan bermakna. Untuk konsentrasi $20 \%$ tidak ada perbedaan bermakna dengan konsentrasi $10 \%$ namun memiliki perbedaan bermakna dengan konsentrasi $40 \%$, kontrol negatif dan kontrol positif. Untuk konsentrasi 40\% memiliki konsentrasi bermakna dengan seluruh konsentrasi lain juga terhadap kontrol negatif dan kontrol positif.

Buah sirih memiliki kandungan alkaloid yang merupakan senyawa antibakteri. Hal ini didukung oleh penelitian Supomo yang menyatakan bahwa kulit buah manggis yang memiliki kandungan alkaloid, memiliki potensi antibakteri. ${ }^{16}$ Alkaloid memiliki kemampuan sebagai antibakteri dengan mekanisme mengganggu komponen penyusun peptidoglikan pada sel bakteri, sehingga lapisan dinding sel tidak terbentuk secara utuh dan menyebabkan kematian sel tersebut. ${ }^{1}$

Kontrol negatif yang digunakan adalah DMSO yang menunjukkan tidak adanya zona hambat. Pelarut DMSO merupakan pelarut organik dan tidak bersifat bakterisidal. ${ }^{17}$ Kontrol positif yang digunakan adalah kertas cakram tetrasiklin dengan konsentrasi kertas cakram 30 $\mu$ g tetrasiklin hasil yang didapat untuk antibakteri adalah sedang dikarenakan menurut Busyron kertas cakram tetrasiklin sudah memiliki resistensi sebesar $87,5 \%$ terhadap bakteri gram positif. ${ }^{18}$

\section{SIMPULAN}

Ekstrak buah sirih memiliki kandungan alkaloid. Alkaloid tersebut berada pada panjang gelombang maksimum 282 nm. Hasil uji aktivitas antibakteri ekstrak buah sirih terhadap bakteri Staphylococcus epidermidis memiliki aktivitas antibakteri kuat pada semua konsentrasi yang dinilai.

\section{Konflik Kepentingan}

Penulis menyatakan tidak terdapat konflik kepentingan dalam studi ini.

\section{DAFTAR PUSTAKA}

1. Wehantouw F, Manurung S, Suryanto E. Aktivitas antihiperglikemik ekstrak kulit manggis (Garcinia Mangostana L.) pada tikus yang diinduksi sukrosa. Chem Prog 2011;4(2):89-96. 
2. Dalimartha S. Atlas Tumbuhan Obat Indonesia Jilid 4. Cetakan kedua. Jakarta: Puspa Swara, 2007.

3. Sheikh M, Malik AR, Meghavanshi MK, Mahmood I. Studies on some plant extract for their antimicrobial potential against certain pathogennic microorganisms. Am J Plant Sci 2012;3:209-13.

4. Priyono SH, Praptiwi. Identifikasi senyawa kimia dan aktivitas antibakteri ekstrak piper sp. asal Papua. Jurnal Teknologi Lingkungan 2009;10 (3):271-6.

5. Darmawati AASK, Bawa IGAG, Suirta IW. Isolasi dan identifikasi senyawa golongan flavonoid pada daun nangka (Artocarpus heterophyllus Lmk) dan aktivitas antibakteri terhadap bakteri Staphylococcus aureus. Jurnal Kimia 2015;9(2): 203-10.

6. Chairani A, Harfiani E. Efektivitas getah jarak sebagai antiseptik terhadap pertumbuhan Staphylococcus aureus, Escherichia coli dan Candida sp. secara in vitro. Jurnal Kedokteran Unila 2018;2(2):84-92.

7. Brooks GF, Butel JS, Morse SA. Jawetz, Melnick, \& Adelberg Mikrobiologi Kedokteran. Edisi 23. Alih bahasa: Hartanto $\mathrm{H}$, Rachman $\mathrm{C}$, Dimanti A, Diani A. Editor edisi bahasa Indonesia: Elferia RN dkk. Jakarta: EGC, 2007.

8. Anshori M, Iswanti S. Buku Ajar: Metodologi Penelitian Kuantitatif. Surabaya: Airlangga University Press, 2009.

9. Kristanti AN, Aminah NS, Tanjung M, Kurniadi B. Buku Ajar Fitokimia. Surabaya: Airlangga University Press, 2008.

10. Pranata FS. 1997. Isolasi alkaloid dari bahan alam. Biota;2(2):96-9.

11. Hsieh TJ, Wu YC, Chen SC, Huang CS, Chen CY. Chemical constituents from Annona Glabra. J Chinese Chem Soc. 2013 51:869-76.

12. Harbone JB. Metode fitokimia penuntun cara modern menganalisis tumbuhan. Bandung: ITB, 1987.

13. Hammado N, Illing I. Identifikasi senyawa bahan aktif alkaloid pada tanaman lahuna (Eupatorium odoratum). Jurnal Dinamika. 2013; 4(2):1-18.

14. Yanti M. Isolasi dan identifikasi senyawa alkaloid dalam ekstrak daun sirsak hutan (Annona glabra). [Skripsi]. Bogor: Institut Pertanian Bogor, 2014. Available from: https://pdfs.semanticscholar.org/8 211/403c344c552e40d8ddf839eb8 851d43cf785.pdf

15. Bhaumik PK, Mukherjee B, Juneau JP, Bhacca NS, Mukherjee R. Alkaloids from leaves of Annona squamosa. Phytochemistry. 1979; 18(9):1584-6.

16. Supomo, Syamsul ES, Rukmana. Uji aktivitas anti bakteri ekstrak etanol kulit buah manggis (Garcinia mangostana L.) terhadap bakteri Staphylococcus epidermidis ATCC 49461. Jurnal Ilmu Kesehatan. 2015;3(2). Available from: https:// docplayer.info/33522659-Ujiaktivitas-anti-bakteri-ekstraketanol-kulit-buah-manggisgarciniamangostanal-terhadapbakteri-staphylococcusepidermidis-atcc49461.html

17. Assidqi K, Tjahjaningsih W, Sigit S. Potensi ekstrak daun patikan kebo (Euphorbia hirta) sebagai antibakteri terhadap Aeromonas hydrophila secara in vitro. Journal of Marine and Coastal Science. 2012; 1(2):113-24.

18. Chudlori B, Kuswandi M, Indrayudha P. Pola kuman dan resistensi terhadap antibiotika dari spesimen pus di RSUD Dr. Moewardi tahun 2012. Pharmacon 2012;13(2):70-6 